\title{
Acute Mountain Sickness (AMS) Knowledge Among High Altitude Marathon Runners Competing in the Everest Marathon
}

\author{
Abigail Letchford, MBChB; Rudra Paudel, MD; Owen D. Thomas, MBChB (Hons); Adam S. Booth, MRGP; \\ Christopher H.E. Imray, FRCS \\ From the Medical School, University of Birmingham, Birmingham, UK (Dr Letchford); the Internal Medicine, Icahn School of Medicine at Mount \\ Sinai, New York, NY (Dr Paudel); the Sandwell and West Birmingham Hospitals NHS Trust, Birmingham, UK (Dr Thomas); the Locum GP, \\ Shropshire, UK (Dr Booth); and the University of Warwick and the University Hospital Coventry and Warwickshire NHS Trust, Coventry, \\ UK (Dr Imray).
}

\begin{abstract}
Objective.-Although there are a number of studies on trekkers' knowledge of acute mountain sickness (AMS), there is little current literature on other groups at altitude, for example, marathon runners. Increased knowledge of AMS is associated with a lower incidence of AMS. The purpose of this study was to determine AMS knowledge of marathon runners with an aim to improve AMS information distribution. Incidence of AMS was also determined.

Methods.-Participants completed a self-assessment AMS knowledge questionnaire in Kathmandu before starting the acclimatization trek for the Tenzing Hillary Everest Marathon in Nepal. Lake Louise Scoring questionnaires were completed every day of the 12-day acclimatization trek.

Results.-The majority ( $86 \% ; 43$ of 50) of participants obtained information about AMS before the marathon, with the Internet providing the most common source $(50 \% ; 25$ of 50). Ninety-two percent (46 of 50) of participants rated their knowledge as average or above, and self-assessment correlated with knowledge questionnaire scores $(r=.479, P<.001)$. However, 48\% (24 of 50) did not know it was unsafe to ascend with mild AMS symptoms, and 66\% (33 of 50) thought it was safe to go higher with symptoms relieved by medication. Only 50\% (25 of 50) knew AMS could occur from $2500 \mathrm{~m}$. Thirty-eight percent (19 of 50) of participants had AMS during the acclimatization trek, and 6\% (3 of 50) experienced it during the race.

Conclusions.-This study adds to previous literature regarding knowledge and incidence of AMS. It further highlights that more needs to be done to improve knowledge through better information dissemination, with inclusion of scenario-based information to aid application of this knowledge to practical situations.
\end{abstract}

Key words: altitude sickness, knowledge, marathon runners, Nepal

\section{Introduction}

Ascent to high altitude is becoming increasingly popular and accessible. Those traveling to altitudes above $2500 \mathrm{~m}$ are at risk of developing acute mountain sickness (AMS), high altitude cerebral edema, or high altitude pulmonary edema. ${ }^{1}$ The Lake Louise Consensus Group defined AMS as the presence of a cardinal headache after a recent gain in altitude, with one or more of the following symptoms: gastrointestinal symptoms, fatigue, dizziness, or insomnia. ${ }^{2}$

Corresponding author: Abigail Letchford, MBChB, The Medical School, Vincent Drive, University of Birmingham, Birmingham, B15 2TT UK (e-mail: abi.letchford@gmail.com).
Slow ascent reduces the risk of AMS. Above $3000 \mathrm{~m}$, sleeping elevation should not be increased by more than $500 \mathrm{~m}$ a day, and a rest day should be included every 3 to 4 days. The use of acetazolamide is recommended prophylactically (125 mg twice daily) if a gradual ascent cannot be followed or there is a prior history of AMS. ${ }^{1}$

In the Himalayas, observational studies suggest AMS incidence ranges from $14 \%$ to $53 \%$ in foreign visitors. ${ }^{3}$ A study comparing incidence in porters and trekkers concluded that accessible knowledge needs to be improved to help increase understanding and reduce incidence. ${ }^{3}$ However, even with knowledge of AMS, trekkers in the Himalayas did not always act on it. ${ }^{4}$ Lack 
of knowledge is also seen among trekkers in other areas, with observations in Cuzco, Peru, illustrating a general lack of AMS awareness in foreign travelers. ${ }^{5}$ Previous studies have proven that a better understanding of altitude illness reduces incidence. ${ }^{6}$

Although there have been several observational studies on trekkers' knowledge, there is little current literature on AMS knowledge in those undertaking other activities at altitude, such as marathons. These participants all have different goals, levels of fitness, prior exposure to altitude, and access to knowledge about AMS.

The marathon industry is growing fast, with people wanting to compete in more challenging marathons, and races at altitude provide this opportunity. There are several high altitude marathons, the highest of which is the Tenzing Hillary Everest Marathon (THEM). ${ }^{7}$ Given the severity of some cases of AMS, it is important to gather information on different groups visiting altitude for recreation to gain a better understanding of their knowledge before going to altitude. These data can then be used to optimize information dissemination and help minimize AMS incidence.

The purpose of this study was to determine AMS knowledge of marathon runners, with an aim to improve AMS information distribution, especially for high altitude endurance events. Incidence of AMS was also determined.

\section{Methods}

The THEM, based in the Khumbu region of Nepal, is an annual 42-km run from Everest Base Camp (5365 m) to Namche Bazaar $(3440 \mathrm{~m})$, open to both Nepali and international competitors. ${ }^{7}$ In 2014, however, because of poor weather conditions, competitors started at Gorak Shep (5100 m), with an extra loop added to maintain the course length. Most of the international competitors participate in a 12-day acclimatization trek beginning at Lukla $(2860 \mathrm{~m})$ and ending at Everest Base Camp $(5365 \mathrm{~m})$. This has a standardized ascent profile to reach the start line and complies with the Wilderness Medical Society Consensus guidelines for a safe ascent. ${ }^{1}$

All runners participating in the acclimatization trek were approached to be participants at the race briefings in Kathmandu (1200 m). Informed written consent was obtained, and a questionnaire was completed to ascertain their prior knowledge of AMS. Daily Lake Louise selfassessment Score (LLS) questionnaires were completed on the ascent from Lukla. A diagnosis of AMS was made if participants had a headache with an LLS greater than $3 .^{2}$ Participants with AMS were offered a consultation with an expedition doctor. Any medication taken by participants for prophylaxis or treatment of AMS was recorded. A postmarathon questionnaire was completed, incorporating an LLS applicable to symptoms during the marathon.

A knowledge questionnaire (Appendix 1) was written, incorporating questions from previous papers that looked at knowledge of visitors to high altitude. ${ }^{5,6,8,9}$ It was reviewed by members of the Birmingham Medical Research Expeditionary Society to assess whether it was suitable. An overall knowledge score was created using the information from the questionnaire (Table 1).

All data were entered into Microsoft Excel (Microsoft Corp, Redmond, WA) and transferred to SPSS version 22 (IBM Corp, Armonk, NY). Data were summarized using percentages and means. A Student's $t$ test was used to see whether obtaining prior knowledge increased participants' knowledge. Spearman's correlation was used to analyze questionnaire scores. Significance was assumed at a probability value $>.05$ when appropriate.

Ethical approval was granted by the University of Birmingham and the Nepal Health Research Council (2071-2-1).

\section{Results}

There were 36 Nepali and 95 international competitors. None of the Nepali competitors undertook the

Table 1. Scoring system for overall knowledge score

\begin{tabular}{lc}
\hline Answer & $\begin{array}{c}\text { Maximum } \\
\text { points available }\end{array}$ \\
\hline AMS can be prevented by medication & 1 \\
$\quad$ - Acetazolamide & 1 \\
AMS can be prevented by other methods & 1 \\
$\quad$ - Slow ascent, hydration & 2 \\
Headache is the main symptom of AMS & 1 \\
Number of correct other main symptoms & 4 \\
Symptoms can occur from 2500 m & 1 \\
AMS symptoms can be relieved by & 1 \\
medication & 1 \\
AMS can be treated & 3 \\
- Descent, oxygen, acetazolamide, & \\
$\quad$ dexamethasone, ibuprofen & 1 \\
AMS has more serious complications & 2 \\
$\quad$ - HACE, death & \\
Signs AMS is getting more serious & \\
- Altered mental state, drowsy, ataxia, & \\
$\quad$ coma, decreased exercise tolerance, dry & \\
$\quad$ cough, worsening headache & \\
Scenario questions (Table 4) & \\
Total & 27 \\
\hline
\end{tabular}

AMS, acute mountain sickness; HACE, high altitude cerebral edema. 
acclimatization trek; therefore, they were not included in the study. Sixty-nine international competitors participated in the trek. Reasons for exclusions included not understanding English (1.4\%; 1 of 69), being the principal investigator $(1.4 \%$; 1 of 69$)$, only partially completing the questionnaires $(1.4 \% ; 1$ of 69$)$, and not receiving complete instructions from a doctor assisting in data collection $(23.2 \%$; 16 of 69$)$. This resulted in $72.5 \%$ (50 of 69) participation. The demographics are shown in Table 2. The median age was 43 (SD, \pm 10.40$)$. Prior experience of participants is shown in Table 3.

Awareness of AMS prophylaxis was moderate, with $62 \%$ (31 of 50) aware that medications could help, of which $97 \%$ (30 of 31) knew about acetazolamide. Seventy-six percent (38 of 50) were aware of other methods, with $82 \%$ (31 of 38) mentioning slow ascent and 53\% (20 of 38) mentioning good hydration. Only $50 \%$ (25 of 50) correctly identified $2500 \mathrm{~m}$ as the altitude at which symptoms can start to occur.

Seventy-two percent (36 of 50) correctly identified the main symptom of AMS as headache. The number of correct answers for the remaining main symptoms of AMS were recorded, with $18 \%$ (9 of 50) not naming any, $28 \%$ (14 of 50) naming 1, 40\% (20 of 50) naming 2, $12 \%$ (6 of 50) naming 3 and 1 person identifying all 4 .

The majority $(88 \%$; 44 of 50$)$ knew symptoms could sometimes be relieved by medication. Seventy-three percent (32 of 44) knew about acetazolamide, and 5\% (2 of 44) knew about dexamethasone. Seventy-six percent (38 of 50) carried medications, with $74 \%$ (28 of 38) bringing acetazolamide.

Ninety-two percent (46 of 50) knew AMS could be treated, with $83 \%$ (38 of 46) listing descent and 17\% (8 of 46) mentioning oxygen, but only $4 \%$ ( 2 of 46 ) knew about acetazolamide and dexamethasone, despite many knowing acetazolamide could be used as prophylaxis. Eighty-six percent (43 of 50) knew there were more serious complications of AMS; 49\% (21 of 43) knew about high altitude cerebral edema and 42\% (18 of 43) mentioned death. Participants were asked 4 scenario questions, and the answers are shown in Table 4.

The Figure represents the overall AMS knowledge scores. The mean score was 13.8 of 27 (SD, \pm 3.97 ). There was no significant difference between participants who obtained information before coming to Nepal and those who did not with regard to their knowledge score (14.2 and 11.4, respectively; $P=.083$ ). There was no correlation between a participant's scenario scores and overall knowledge scores $(r=.159 ; P=.269)$. There was a good correlation between a participant's personal rating of their knowledge of AMS when compared with their overall knowledge score $(r=$ $.449 ; P=.001)$.
Table 2. Demographics of study population

\begin{tabular}{|c|c|c|}
\hline Demographics & $\begin{array}{l}\text { Number of } \\
\text { participants } \\
(\text { total }=50)\end{array}$ & Percentage \% \\
\hline \multicolumn{3}{|l|}{ Sex } \\
\hline Male & 30 & 60 \\
\hline Female & 20 & 40 \\
\hline \multicolumn{3}{|l|}{ Nationality } \\
\hline American & 3 & 6 \\
\hline Australian & 7 & 14 \\
\hline Belgian & 1 & 2 \\
\hline Brazilian & 1 & 2 \\
\hline British & 20 & 40 \\
\hline Canadian & 1 & 2 \\
\hline Dutch & 2 & 4 \\
\hline German & 1 & 2 \\
\hline Indian & 1 & 2 \\
\hline Israeli & 1 & 2 \\
\hline Japanese & 1 & 2 \\
\hline Malaysian & 1 & 2 \\
\hline New Zealander & 4 & 8 \\
\hline Polish & 1 & 2 \\
\hline Swedish & 1 & 2 \\
\hline South African & 3 & 6 \\
\hline Thai & 1 & 2 \\
\hline \multicolumn{3}{|l|}{ Education } \\
\hline $\begin{array}{l}\text { Did not complete high } \\
\text { school }\end{array}$ & 1 & 2 \\
\hline Secondary school & 9 & 18 \\
\hline Bachelor's degree & 23 & 46 \\
\hline Master's degree & 12 & 24 \\
\hline Doctoral degree & 5 & 10 \\
\hline \multicolumn{3}{|l|}{ Current occupation } \\
\hline Healthcare professional & 8 & 16 \\
\hline $\begin{array}{l}\text { Job that involves exposure } \\
\text { to knowledge of AMS }\end{array}$ & 7 & 14 \\
\hline $\begin{array}{l}\text { Job that does not involve } \\
\text { exposure to knowledge of } \\
\text { AMS }\end{array}$ & 35 & 70 \\
\hline \multicolumn{3}{|l|}{$\begin{array}{l}\text { Worked in healthcare } \\
\text { profession? }\end{array}$} \\
\hline Yes & 11 & 22 \\
\hline No & 39 & 78 \\
\hline \multicolumn{3}{|l|}{$\begin{array}{l}\text { Career increased knowledge } \\
\text { of AMS? }\end{array}$} \\
\hline Yes & 17 & 34 \\
\hline No & 33 & 66 \\
\hline \multicolumn{3}{|l|}{ Home altitude } \\
\hline $0-500 \mathrm{~m}$ & 29 & 58 \\
\hline $500-1000 \mathrm{~m}$ & 13 & 26 \\
\hline $1000-1500 \mathrm{~m}$ & 8 & 16 \\
\hline
\end{tabular}

AMS, acute mountain sickness.

During the acclimatization trek, $44 \%$ (22 of 50) experienced AMS at some point. However, many 
Table 3. Information from questionnaire

\begin{tabular}{|c|c|c|}
\hline Information & $\begin{array}{l}\text { Number of } \\
\text { participants }\end{array}$ & $\begin{array}{c}\text { Percentage } \\
\%\end{array}$ \\
\hline Prior experience of high altitude & $40 / 50$ & 80 \\
\hline $\begin{array}{l}\text { AMS at high altitude } \\
\text { previously }\end{array}$ & $8 / 40$ & 20 \\
\hline $\begin{array}{l}\text { Previous marathon at high } \\
\text { altitude }\end{array}$ & $12 / 50$ & 24 \\
\hline $\begin{array}{l}\text { AMS during previous } \\
\text { marathon }\end{array}$ & $1 / 12$ & 8 \\
\hline $\begin{array}{l}\text { Obtained information before } \\
\text { marathon }\end{array}$ & $43 / 50$ & 86 \\
\hline \multicolumn{3}{|l|}{$\begin{array}{l}\text { Sources of AMS information } \\
\text { (more than } 1 \text { source per } \\
\text { participant) }\end{array}$} \\
\hline Internet & $25 / 50$ & 50 \\
\hline Doctors & $20 / 50$ & 40 \\
\hline Family/friends & $19 / 50$ & 38 \\
\hline Guidebooks & $12 / 50$ & 24 \\
\hline Work & $6 / 50$ & 12 \\
\hline Medical literature & $2 / 50$ & 4 \\
\hline Other & $6 / 50$ & 12 \\
\hline \multicolumn{3}{|l|}{ Personal rating of knowledge } \\
\hline Very good & $4 / 50$ & 8 \\
\hline Good & $13 / 50$ & 26 \\
\hline Average & $29 / 50$ & 58 \\
\hline Poor & $4 / 50$ & 8 \\
\hline Very poor & $0 / 50$ & 0 \\
\hline $\begin{array}{l}\text { Participants wanting to know } \\
\text { more about AMS }\end{array}$ & $44 / 50$ & 88 \\
\hline
\end{tabular}

AMS, acute mountain sickness.

participants also had gastroenteritis, unrelated to altitude. This was diagnosed by the doctors and treated with azithromycin. These symptoms would have a potential confounding influence. A note of the days when participants had gastroenteritis was made, and when these days were removed, $38 \%$ (19 of 50) experienced AMS.

Six percent ( 3 of 50) of participants experienced AMS during the race. One participant vomited, but completed the race and was subsequently treated with IV fluids for 2 days.

\section{Discussion}

This study shows there are substantial gaps in AMS knowledge, even in a population completing high altitude events. There was a low incidence of previous AMS reported, and this may be because of underreporting or misunderstanding of the symptoms. The main sources of information differ slightly from a study conducted on travelers to Cuzco in 2007, in which guidebooks (52\%) and doctors (24\%) were the most widely used sources. ${ }^{5}$ The increased Internet use may be a result of it becoming more ubiquitous in the last 7 years.

In comparison with observations of AMS awareness in laypeople and trekkers using similar assessments, this population appeared to have a higher level of knowledge. ${ }^{4,6,8,9}$ Correlation showed individuals were generally good at assessing their own level of knowledge. There was poor correlation between the scenario score and overall knowledge score, which indicates that people did not apply their knowledge correctly to the scenarios. Alarmingly, only $52 \%$ knew it was unsafe to go to a higher altitude with symptoms of AMS, compared with $66 \%$ in the Cuzco study. However, $88 \%$ knew to descend if experiencing worsening symptoms, compared with $77 \%$ in the Cuzco study, and $98 \%$ knew to always accompany someone with AMS, compared with $85 \%$ in the Cuzco study. ${ }^{5}$ It was interesting to note that participants who obtained information before coming to Nepal did not have a greater knowledge. This lack of application of knowledge is concerning among those competing in high altitude endurance events because of the potential risks of continuing to ascend and participate despite symptoms.

Atmospheric pressure falls with increasing altitude, resulting in a lower partial pressure of inspired oxygen. As a consequence, individuals become hypoxic, which is reflected by a reduction in peripheral arterial saturations. Exercise at that altitude results in a further desaturation or an exercise-induced hypoxemia (an increase in "virtual altitude"). Mechanisms include a more rapid transit of red blood cells through the pulmonary vascular bed, combined with the lower oxygen gradient. As a result, red blood cells traverse the pulmonary bed before they are fully uploaded with oxygen. The "live high, train high" approach to performance training uses these physiological mechanisms to stimulate the adaptive process, such as erythropoietin secretion, to increase the hematocrit and so enhance subsequent performance. ${ }^{10}$ It may be useful to include activity-specific scenarios in the literature in future to help participants apply knowledge.

Only $50 \%$ correctly identified $2500 \mathrm{~m}$ as the altitude at which symptoms of AMS can start to occur. In a Himalayan study, $15 \%$ believed AMS started at $4000 \mathrm{~m}^{4}$ This lack of knowledge needs to be addressed.

Awareness of acetazolamide for prophylaxis was much higher than in a Himalayan study on trekkers, in which only $32 \%$ knew about acetazolamide and only $9 \%$ from the Cuzco study knew about it. ${ }^{4,5}$ The use of acetazolamide to prevent AMS is understandable, but because it also has a potential performance-enhancing effect, its use in a competitive race clearly raises 
Table 4. Scenario questions from the knowledge questionnaire

\begin{tabular}{|c|c|c|c|}
\hline Scenario question & $\begin{array}{l}\text { Correct } \\
\text { answer }\end{array}$ & $\begin{array}{l}\text { Number of } \\
\text { participants } \\
\text { (total }=50)\end{array}$ & Percentage \% \\
\hline 1. Is it safe to go to a higher altitude with mild symptoms of AMS? & No & 26 & 52 \\
\hline $\begin{array}{l}\text { 2. If you have symptoms of AMS that are alleviated with medication, is it safe to } \\
\text { go to a higher altitude? }\end{array}$ & No & 17 & 34 \\
\hline $\begin{array}{l}\text { 3. Is it safe to stay at the same altitude to recover if you have been experiencing } \\
\text { worsening symptoms of AMS and cannot walk heel-to-toe in a straight line? }\end{array}$ & No & 44 & 88 \\
\hline 4. Does someone always have to accompany an ill person with AMS? & Yes & 49 & 98 \\
\hline \multicolumn{4}{|l|}{ Number of correct answers (scenario score) } \\
\hline 0 & & 1 & 2 \\
\hline 1 & & 1 & 2 \\
\hline 2 & & 17 & 34 \\
\hline 3 & & 23 & 46 \\
\hline 4 & & 8 & 16 \\
\hline
\end{tabular}

AMS, acute mountain sickness.

potential ethical issues. Knowledge that symptoms could be relieved and AMS can be treated was good; however, only $4 \%$ knew that acetazolamide and dexamethasone can be used to treat AMS despite the generally high level of awareness of acetazolamide as prophylaxis; this is compared with $11 \%$ of skiers in North America. ${ }^{8}$ Only $17 \%$ knew about oxygen treatment, similar to trekkers in a Himalayan study. ${ }^{4}$ This needs to be addressed so that people are given the correct information.

The incidence of AMS was $38 \%$, which falls within the middle of the range quoted for the Himalayas of $14 \%$ to $53 \% .^{3}$ The acclimatization trek fulfilled the Wilderness Medical Society Consensus guidelines for a safe ascent; therefore, increased education is unlikely to reduce the incidence in this cohort. However, it will be important for those not participating in organized acclimatization treks. ${ }^{1}$ It is interesting to note the slight difference in those diagnosed with AMS when the values for those who had gastroenteritis are removed. This indicates that the Lake Louise Scoring system can be skewed by illness other than that caused by altitude.

Interestingly, only $6 \%$ of runners had AMS during the marathon. This may be related to the ability to acclimatize before the race and the race profile, which had a large descent before any significant ascents. It is also important to recognize that other factors may lead to the symptoms similar to AMS, such as dehydration, solar exposure, and diet before the race.

The THEM organizers are keen to incorporate findings from this study into future event literature. It may be useful for participants to receive information via e-mail or post so they can arrive with a better understanding. A tick box on the entry form could be included for acknowledgment that the information has been read.

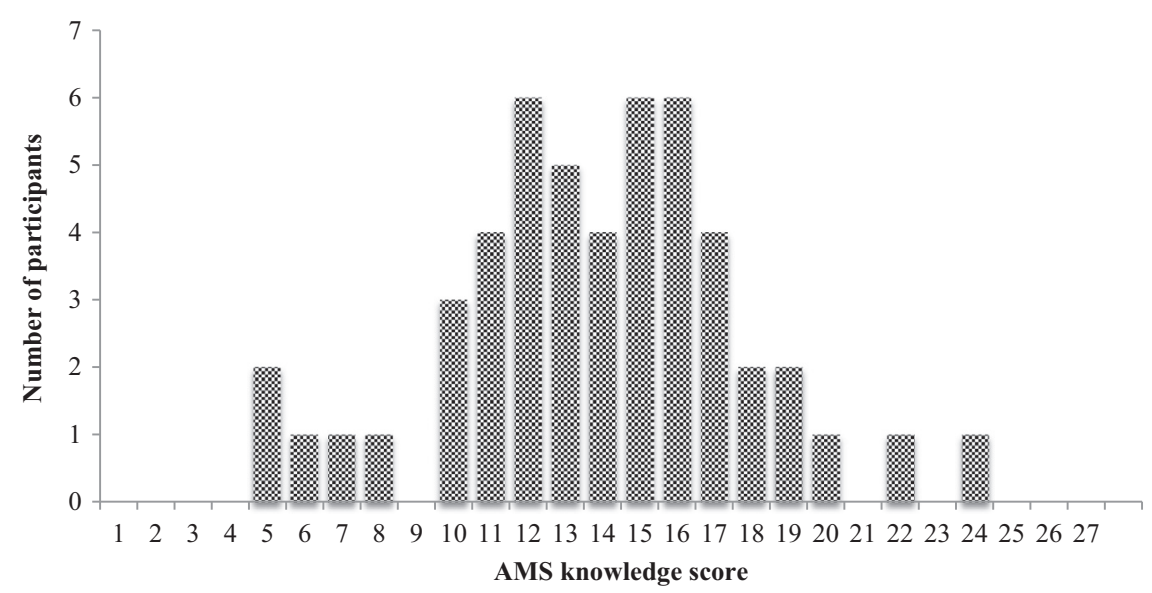

Figure. Acute mountain sickness (AMS) knowledge scores. 
Merritt et al $^{5}$ suggest that guidebooks that feature high altitude destinations should ensure an up-to-date section on AMS. Efforts have already been made by the International Porter Protection Group, Himalayan Rescue Association, and Kunde Hospital in the Khumbu region to educate visitors. ${ }^{3}$ Furthermore, as information is regularly sought from doctors, they should provide information sources for patients.

\section{Limitations}

The knowledge questionnaire was not validated before use; however, it incorporated questions used in previous research and comparisons have been drawn to these data. Wording of questions was modified slightly without altering the content. In hindsight, the wording of some questions could be improved. Question 13 could be changed to "Do you think AMS can sometimes be prevented by certain methods or strategies?" Question 18 could be changed to "Do you think symptoms of AMS can sometimes be relieved by medication(s)?" Answers from question 19 were not included because of its ambiguity.

It is important to note the limitation of self-reporting for AMS diagnosis using the LLS questionnaires. Many people underreport symptoms as a result of denial, undereducation, or fear they cannot continue with their trip. Participants' medical history was not collected, but some conditions may have caused symptoms similar to AMS, which may have led to an overestimate of the incidence.

This study was of only 1 marathon, and therefore is not representative of all high altitude marathon runners, but it does provide a good insight into their knowledge. Further studies may be of benefit to obtain a more representative sample. It would also be interesting to see whether marathon runners perceived their fitness as protective in developing AMS despite the literature stating otherwise. ${ }^{2}$

Nepali competitors could not be included, but 17 of the top 20 finishers were Nepali. This may be related to living or spending time in the preceding weeks at altitude or a genetic advantage.

\section{Conclusions}

This study adds to the previous literature on knowledge of visitors including marathon runners to high altitude and also incidence of AMS. It highlights that more needs to be done to improve knowledge through better information dissemination, with inclusion of scenariobased information to aid application of this knowledge to practical situations.

\section{Acknowledgments}

We would like to thank the participants and Shikhar Pandey and the other marathon organizers for their logistical assistance, and Dr Yadunath Pokharel for his help with data collection.

We are also very grateful for the financial contributions from the British Medical and Dental Students' Trust Elective Travel Research Award, The Roger and Miriam Pilkington Charitable Trust Grant, and Onnesley Trust Elective Support Bursary.

\section{Appendix. Supplementary Materials}

Supplementary material cited in this article is available online at http://dx.doi.org/10.1016/j.wem.2015.09.021.

\section{References}

1. Luks AM, McIntosh SE, Grissom CK, et al. Wilderness Medical Society. Wilderness Medical Society consensus guidelines for the prevention and treatment of acute altitude illness. Wilderness Environ Med. 2010;21:146155.

2. Imray $\mathrm{C}$, Booth $\mathrm{A}$, Wright $\mathrm{A}$, Bradwell A. Acute altitude illnesses. BMJ. 2011;343:d4943.

3. Newcomb L, Sherpa C, Nickol A, Windsor J. A comparison of the incidence and understanding of altitude illness between porters and trekkers in the Solu Khumbu Region of Nepal. Wilderness Environ Med. 2011;22: 197-201.

4. Paz A, Steinfeld I, Potasman I. Are we doing our best to educate travelers about the risks of acute mountain sickness? An on-site prospective study in the Himalayas. J Travel Med. 2007;14:168-172.

5. Merritt AL, Camerlengo A, Meyer C, Mull JD. Mountain sickness knowledge among foreign travelers in Cuzco, Peru. Wilderness Environ Med. 2007;18:26-29.

6. Vardy J, Vardy J, Judge K. Can knowledge protect against acute mountain sickness? J Public Health (Oxf). 2005;27:366-370.

7. Tenzing Hillary Everest Marathon. 2014. Available at: http://www.everestmarathon.com. Accessed August 19, 2014.

8. Hatzenbuehler J, Glazer J, Kuhn C. Awareness of altitude sickness among visitors to a North American ski resort. Wilderness Environ Med. 2009;20:257-260.

9. Subedi D, Marahatta R, Sharma S, Bajracharya R, Hillenbrand P, Soon Y. Trekkers' awareness of acute mountain sickness and acetazolamide. Wilderness Environ Med. 2008;19:321-322.

10. Major SA, Hogan RJ, Yeates E, Imray CH. Peripheral arterial desaturation is further exacerbated by exercise in adolescents with acute mountain sickness. Wilderness Environ Med. 2012;23:15-23. 